\title{
Entry exclusion in F-like plasmids requires intact TraG in the donor that recognizes its cognate TraS in the recipient
}

Correspondence

Laura S. Frost

laura.frost@ualberta.ca

Received 28 August 2006

Revised 30 October 2006

Accepted 2 November 2006

\author{
Gerald F. Audette, $†$ Jan Manchak, Perrin Beatty, William A. Klimkeł \\ and Laura S. Frost
}

Department of Biological Sciences, CW-405 Biological Sciences Building, University of Alberta, Edmonton, AB T6G 2E9, Canada

\begin{abstract}
The mating pair stabilization (Mps) protein of the F plasmid, TraG, is unique to F-like type IV secretion systems. TraG is a polytopic inner-membrane protein with a large $\mathrm{C}$-terminal periplasmic domain that is required for piliation and $\mathrm{Mps}$, whereas the $\mathrm{N}$-terminal region is sufficient for pilus synthesis. The C-terminal region of TraG is thought to be cleaved by the host signal peptidase I to give a fragment called TraG* that is responsible for Mps. Using mutational analysis and cell localization studies, it was shown that $\mathrm{TraG}^{*}$ is most probably an artifact caused by non-specific degradation. TraS (173 aa in F), which is involved in entry exclusion (Eex), blocks redundant conjugative DNA synthesis and transport between donor cells, suggesting that it interferes with a signalling pathway required to trigger DNA transfer. Using the F and R100 plasmids, TraG in the donor cell was found to recognize TraS in the recipient cell inner membrane, in a plasmid-specific manner. This activity mapped to aa 610-673 in F TraG, the only region that differs significantly from R100 TraG. Expression of traG or traG ${ }^{*}$ in a recipient cell did not affect mating ability or Eex. These results suggest that TraG may be translocated to the recipient cell, where it contacts the inner membrane, initiating transfer, a process that is blocked by TraS.
\end{abstract}

\section{INTRODUCTION}

Bacterial conjugation is the transfer of plasmid DNA from a donor to a recipient cell, thereby distributing new genetic elements and other adaptations for survival in unique environments (Ochman et al., 2000; Wilkins \& Frost, 2001). Although conjugative plasmids have been identified in several bacterial species, the F plasmid from Escherichia coli remains a paradigm for the study of bacterial conjugation (Lawley et al., 2004). The $100 \mathrm{~kb} F$ plasmid encodes all genes necessary for conjugation in the $33.3 \mathrm{~kb}$ transfer (tra) region, including genes for pilus synthesis, mating pair formation (Mpf) and DNA transfer (Frost et al., 1994). Conjugative systems have recently been classified as a subset of the type IV secretion system (T4SS), due to the considerable similarity between the genes involved in both processes (Lawley et al., 2003).

tPresent address: Department of Chemistry, 456 Chemistry Building, York University, 4700 Keele St, Toronto, ON M3J 1P3, Canada.

‡Present address: National Center for Biotechnology Information/ National Institutes of Health, 6th Floor, 45 Center Drive, Bethesda, MD 20892, USA.

Abbreviations: Eex, entry exclusion; Mpf, mating pair formation; Mps, mating pair stabilization.
The conjugative transfer of DNA is a plasmid-driven process that involves an intimate association between a donor and recipient cell, termed a mating pair (Lederberg, 1956; Achtman, 1975; Durrenberger et al., 1991). This is followed by the transfer of plasmid ssDNA through a membraneassociated, supramolecular structure known as the $\mathrm{Mpf}$ complex. In F-like systems, mating pair stabilization (Mps) allows cells to mate more efficiently in liquid media, and to more readily resist disaggregation by mechanical forces (Bradley et al., 1980; Manning et al., 1981). Initially, Mps was thought to be mediated through the $\mathrm{F}$ pilus alone. However, further analysis has shown that, whereas the $\mathrm{F}$ pilus is important for initiating Mpf, the TraN and TraG proteins are responsible for the phenotypes of resistance to SDS and shear forces (Achtman et al., 1977). Kingsman \& Willetts (1978) have shown that mutations in traN and traG allow the initiation of conjugative DNA replication in the donor, but not the transfer of radiolabelled F plasmid DNA to the recipient cell. Another F protein, TraU, has been shown to be involved in DNA transfer, but not pilus synthesis, and is tentatively grouped with the Mps proteins (Moore et al., 1990; Lawley et al., 2003). F TraN is a cysteinerich, outer-membrane protein that requires OmpA in the outer membrane of the recipient cell for efficient mating in liquid cultures (Klimke \& Frost, 1998; Klimke et al., 2005). TraN has also been suggested to interact with TraG, 
although this remains unproven (Firth \& Skurray, 1992; Klimke et al., 2005). A counterpoint to Mps is provided by two processes involved in the prevention of redundant DNA transfer between donor cells. The first is surface exclusion (Sfx), encoded by traT, which impedes contact between donor cells carrying the F plasmid (Achtman et al., 1977; Harrison et al., 1992; Klimke et al., 2005). The second process is entry exclusion (Eex), encoded by traS, which prevents the transfer of DNA between equivalent donor cells (Kingsman \& Willetts, 1978). The Eex systems of the closely related plasmids F and R100 are plasmid-specific, whereby the transfer apparatus in the donor cell recognizes, via TraG, the cognate TraS in the recipient cell (Anthony et al., 1999). Recently, the integrating conjugative elements SXT and R391 from Vibrio cholerae and Providencia rettgeri, respectively, have been shown to behave in a similar fashion to TraG, recognizing its cognate TraS during Eex (Marrero \& Waldor, 2005).

At $102.5 \mathrm{kDa}$, F TraG is one of the largest proteins encoded by the tra region of the F plasmid (Frost et al., 1994). Mutations that map to the N-terminal half of F TraG (e.g. traG106, frameshift) affect pilus assembly, whereas mutations in the C-terminal half of F TraG, such as traG101 (frameshift) and traG79 (amber), affect Mps but permit pilus synthesis, as monitored by phage infection (Willetts \& Achtman, 1972; Fig. 1). Antibodies directed towards the Cterminal domain of $\mathrm{F}$ TraG detect two products: full-length F TraG and, within the periplasm, a $50 \mathrm{kDa}$ product named $\mathrm{TraG}^{*}$ (Firth \& Skurray, 1992). This is not to be confused with the TraGp* fusion product that results from in-frame cloning of the proximal end of $\operatorname{tra} G$ to a protein coding sequence in pRS29 via an EcoRI site (Manning et al., 1981). Sequence analysis of TraG predicts the presence of a signal peptidase I cleavage site after residue 451, generating a
$52.7 \mathrm{kDa}$ product that could be $\mathrm{TraG}^{*}$, which may be released into the periplasmic space and contribute to Mps (Firth \& Skurray, 1992).

In the current study, we confirmed the localization and topology of F TraG, and determined that the middle portion of TraG was responsible for TraS recognition during Eex. $\mathrm{TraG}^{*}$ is likely to be an artifact caused by degradation during cell disruption and protein isolation. We demonstrated that Mps required the presence of full-length TraG, rather than $\mathrm{TraG}^{\star}$ (aa 452-938), within the donor cell. Finally, we noted that Eex was achieved through interaction of TraG and TraS in trans, as co-expression of TraG and TraS in recipient cells did not interfere with mating efficiency or Eex.

\section{METHODS}

Bacterial strains, plasmids and growth conditions. Cells were grown in Luria-Bertani (LB) broth $(\mathrm{BDH})$ at $37^{\circ} \mathrm{C}$ with appropriate antibiotics on a tube roller. Glucose was added to cultures to a final concentration of $0.4 \%$ to repress expression from an IPTG- or arabinose-inducible promoter. Antibiotics (Sigma) were added to the following final concentrations: ampicillin $50 \mu \mathrm{g} \mathrm{ml}^{-1}$; chloramphenicol $20 \mu \mathrm{g} \mathrm{ml}^{-1}$; kanamycin (Km) $25 \mu \mathrm{g} \mathrm{ml}^{-1}$; spectinomycin (Sp) $100 \mu \mathrm{g} \mathrm{ml}^{-1}$; streptomycin (Sm) $200 \mu \mathrm{g} \mathrm{ml}^{-1}$; tetracycline $10 \mu \mathrm{g} \mathrm{ml}^{-1}$ and nalidixic acid (Nal) $16 \mu \mathrm{g} \mathrm{ml}^{-1}$. Arabinose was added to $0.1 \%$ for expression from pBAD vectors. E. coli XK1200 $\left(\mathrm{F}^{-} \mathrm{Nal}^{\mathrm{r}}\right)$ and MC4100 $\left(\mathrm{F}^{-} \mathrm{Sm}^{\mathrm{r}}\right)$ have been described previously (Anthony et al., 1994), as has ED24 (Sp ${ }^{\mathrm{R}}, \mathrm{F}^{-} \mathrm{Lac}^{-}$) (Achtman et al., 1971). Vectors included pBAD24 and pBAD33 (Guzman et al., 1995), pCR-Blunt-TOPO (Invitrogen), pALTER-Ex2 (Promega) and pET26b (Novagen). Conjugative plasmids used included FlactraG79, FlactraG106, FlactraG101 (Achtman et al., 1972) and pOX38::Tc (Anthony et al., 1994). pOX38:: Tc $\Delta$ GKm was constructed by replacing the PstI/PstI fragment in traG of pOX38:: Tc with a Km resistance cassette using recombination, as described by Klimke et al. (2005).

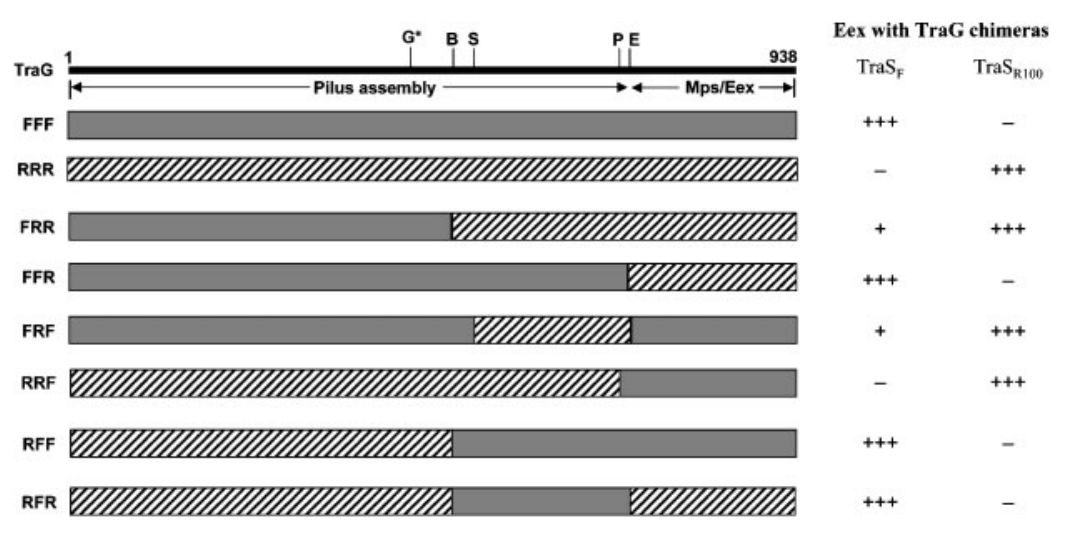

Fig. 1. Depiction of F TraG/R100 TraG chimeras. Chimeras were generated from the $5^{\prime}$ (nt 0-1600), middle (nt 1600-2160) and $3^{\prime}$ (nt 2160-2813) coding regions of $F$ TraG (F) or R100 TraG (R). Restriction endonuclease sites for generation of the chimeras are BstEll (B, nt 1541/aa 514), Smal (S, nt 1600/aa 533), Pstl (P, nt 2154/aa 717) and EcoRI (E, nt 2160/aa 720). Regions of the chimeras arising from $F$ TraG are in solid grey, and regions from R100 TraG are hatched. The predicted signal peptidase cleavage site $\left(G^{*}\right)$ is at residue 451 , and the regions of $\operatorname{TraG}$ involved in pilus assembly and Mps/Eex, according to Frost et al. (1994), are indicated below the line. Beside each chimera are the relative Eex indices observed when the TraG chimeras are present in XK1200/ pOX38::Tc $\Delta \mathrm{Km}$, and F or R100 TraS is present in recipient cells (detailed in Table 3 ). Eex levels are shown as +++ (wild-type),+ (partial) and - (no Eex). 
ISphoA/in insertions into F traG. A $3.0 \mathrm{~kb}$ fragment containing F traG was subcloned into pBSII SK + , which also eliminated the $B a m H I$ site in the multiple cloning site of the vector. This construct, named pBK20, was used to insert ISphoA/in into traG, according to previously described procedures (Manoil \& Bailey, 1997; Klimke et al., 2005). DNA isolated from ISphoA/in derivatives of traG was treated with $B a m \mathrm{HI}$, and the larger DNA fragment was religated to give mutants of $\operatorname{tra} G$ with 31 aa epitopes fused in-frame in the $\operatorname{tra} G$ coding sequence.

Construction of ppelBTraG*. nt $1357-1717$ of the coding region of $\operatorname{TraG}^{*}$ (aa 452-938) were amplified by PCR with Vent polymerase (New England Biolabs), using forward primer LFR193 (5'CCATGGCAGGCAGTGTGG-3') containing an $\mathrm{NcoI}$ site at the $5^{\prime}$ end, and reverse primer G21120 (5'-GCAGTGACTCTGTCACTGG$3^{\prime}$ ), and cloned into pCR-Blunt-TOPO. After NcoI and SmaI digestion, the $5^{\prime}$ proximal portion (front) of traG was moved into a pBAD24 construct carrying the back half (SmaI to $3^{\prime}$ end; nt 1718-2814) of traG to produce $\mathrm{pTraG}^{*}$. The $\operatorname{tra}^{*}$ fragment of this construct was cloned using NcoI and HindIII into pET26b immediately downstream of the pelB leader sequence. The pelB leader sequence and the $\mathrm{TraG}^{*}$ encoding sequence were then recloned into pBAD24, using $X b a I$ and HindIII, generating the plasmid ppelBTraG*.

Generation of traG point mutations. The PstI/Pst fragment from the $\mathrm{F}$ traG gene was cloned into pALTER-Ex2. A mutation was induced in this fragment using the Altered Sites II in vitro Mutagenesis Systems kit (Promega), according to the manufacturer's instructions. The base at position 1353 was changed from $\mathrm{G}$ to $\mathrm{C}$, resulting in an amino acid change from alanine to proline at residue 452. Additional mutations at A449 (A449D) and A451 (A451E) were similarly constructed. The altered DNA was reintroduced into fulllength traG in pBAD24 by restriction digest and ligation, and called pTraGA452P, pTraGA451E and pTraGA449D, respectively.

Construction of chimeric F and R100 TraG and Tras clones. $\mathrm{R} 100$ and $\mathrm{F}$ traG chimeras were constructed using conserved restriction sites in the two genes (Fig. 1). The chimeras were named by referring to the source of the DNA in the $5^{\prime}$ gene fragment (nt 1-1599), middle section (nt 1600-2160) and the $3^{\prime}$ end (nt 2161-2814), using $\mathrm{F}$ and $\mathrm{R}$ for the $\mathrm{F}$ and R100 plasmids, respectively. All constructs with $\mathrm{F}$ sequences in the $5^{\prime}$ region were in the pBAD24 vector, while chimeras starting with the R100 sequence were in pT7.3.

Construction of traS vectors. pTraS-F was prepared by amplification of $\mathrm{F}$ traS using forward primer LFR183 (5'-CCATGGGTAGGGTATGGAG-3') containing a $5^{\prime} \mathrm{NcoI}$ site, and reverse primer LFR184 (5'-AAGCTTTTATTTTACTCTTGATAAC-3') with a 5' HindIII site. The PCR product was ligated into pCR-BluntTOPO, digested from this vector with $\mathrm{NcoI}$ and HindIII, and ligated into pBAD24 digested with the same enzymes. pTraS-R100 was prepared in a similar manner using the forward primer LFR191 ( $5^{\prime}$ CCATGGCTGTTTTTGGGAGATG-3') with a $5^{\prime}$ NcoI site, and reverse primer LFR192 (5'-AAGCTTAAAACGTCATAATATAC-3') containing a $5^{\prime}$ HindIII site. A six-histidine sequence (His6 tag), which was fused to the $\mathrm{N}$ or $\mathrm{C}$ terminus of $\mathrm{F}$ TraS, was similarly constructed, but with the coding sequence for the six histidines included in the primers used for amplification.

Membrane separation by density flotation. Density flotation of cellular membranes was done according to the procedure of Grahn et al. (2000), and isolated cell membranes were resuspended in $2 \mathrm{ml}$ $55 \%$ sucrose. All sucrose solutions (w/v) were made up in $10 \mathrm{mM}$ Tris/ $\mathrm{HCl}, \mathrm{pH} 7.5$, and $5 \mathrm{mM}$ EDTA; gradients were prepared in a stepwise fashion with layers of $0.5 \mathrm{ml} 60 \%$ sucrose, $2 \mathrm{ml}$ sample, $2 \mathrm{ml} 50 \%, 3 \mathrm{ml} 45 \%, 3 \mathrm{ml} 40 \%, 1 \mathrm{ml} 35 \%$ and $0.5 \mathrm{ml} 30 \%$ sucrose. Gradients were centrifuged in a Beckman SW41 rotor at $200000 \mathrm{~g}$ for $72 \mathrm{~h}$. Fractions of $750 \mu \mathrm{l}$ were collected from the top, the protein content of the samples was measured using a Bradford assay (data not shown), and $15 \mu \mathrm{l}$ aliquots of each fraction were analysed by Western blotting for TraG, TraD, OmpA and CpxA, as follows. Proteins from SDS-PAGE were transferred to PVDF membranes, according to the manufacturer's instructions. Identification of TraG, TraD, CpxA and OmpA was done using standard procedures and employed rabbit polyclonal primary antibodies at the following dilutions: anti-TraG, 1:5000; anti-TraD, 1:15000; antiOmpA, 1:100 000; and anti-CpxA, 1:5000. Chemiluminescent detection employed a goat anti-rabbit horseradish peroxidase-conjugated secondary antibody (Amersham) at a dilution of $1: 20000$.

Detection of periplasmic TraG. pBAD24 constructs containing traG, traGA452P, pelBtraG $G^{*}$ and a vector control were transformed into XK1200/pOX38::Tc $\Delta \mathrm{GKm}$. Cultures $(2 \mathrm{ml})$ of these transformants were grown in $\mathrm{LB}$ broth to mid-exponential phase, and induced with $0.1 \%$ arabinose for $1 \mathrm{~h}$ at $37^{\circ} \mathrm{C}$. Periplasmic shock preparation proceeded as follows. Cell pellets from $1.5 \mathrm{ml}$ chilled, induced cultured cells were washed twice in $0.8 \mathrm{ml}$ chilled $10 \mathrm{mM}$ Tris/ $\mathrm{HCl}(\mathrm{pH} 7.5)$ and $30 \mathrm{mM} \mathrm{NaCl}$. The washed cells were pelleted and resuspended in $20 \%$ sucrose and $33 \mathrm{mM}$ Tris ( $\mathrm{pH} 7.5)$, and then EDTA was added to a concentration of $1 \mathrm{mM}$. After incubation at room temperature with gentle rocking for $10 \mathrm{~min}$, the cells were pelleted and resuspended in a small amount of supernatant, and chilled. The resuspended cells were introduced into $10 \mathrm{ml}$ cold $0.5 \mathrm{mM} \mathrm{MgCl}$, containing Complete Mini Protease InhibitorsEDTA (Roche), and stirred gently for $10 \mathrm{~min}$. The resulting shock fluid was cleared of cells by centrifugation, and $0.5 \mathrm{ml}$ aliquots were TCA-precipitated for SDS-PAGE and Western blotting analysis, which proceeded as described above. Samples of induced whole cells $\left(\mathrm{OD}_{600} 0.1\right)$ were also included for comparison.

Mating assays. Mating assays were performed as described by Anthony et al. (1994). Briefly, $2 \mathrm{ml}$ cultures were grown to mid- to late-exponential phase in LB broth with appropriate antibiotics. pBAD constructs were induced with $0.1 \%$ arabinose for $1 \mathrm{~h}$ at $37^{\circ} \mathrm{C}$. Cells were pelleted, washed once with LB broth to remove antibiotics, and resuspended in an equal volume of LB broth. One hundred microlitres each of donor and recipient cells (typically $1 \times 10^{7}$ to $4 \times 10^{8}$ cells $\mathrm{ml}^{-1}$ were used in each mating assay) were mixed with $0.8 \mathrm{ml} \mathrm{LB}$ broth and $0.1 \%$ arabinose for pBAD constructs, and allowed to mate for $45 \mathrm{~min}$ at $37^{\circ} \mathrm{C}$. The mating mixtures were vortexed vigorously and put on ice to prevent further mating. Mating cultures were serially diluted 10 -fold in $4{ }^{\circ} \mathrm{C}$ SSC buffer (150 mM sodium chloride, $15 \mathrm{mM}$ sodium citrate, $\mathrm{pH} 7.0$ ) five times, and $10 \mu \mathrm{l}$ of each dilution was spot-plated separately on agar plates selective for donors, recipients or transconjugants. Colonies were counted after overnight incubation at $37^{\circ} \mathrm{C}$, and the number of transconjugants per 100 donor cells was calculated.

Bioinformatics software. Sequence alignments of $\mathrm{F}$ and R100 TraG and TraS were performed using CLUSTALW (Thompson et al., 1994). Figs. 4 and 5 were prepared with minor manual editing of the CLUSTALW alignments. Transmembrane helices were predicted using TMHMM (Krogh et al., 2001; http://www.cbs.dtu.dk/services/ TMHMM-2.0/).

\section{RESULTS}

\section{Characterization of TraG}

Earlier studies using proteolysis of spheroplasts have shown that TraG localizes within the inner membrane (Firth \& Skurray, 1992). TraG is predicted to contain three (aa 54-73, 
327-385 and 407-447; Firth \& Skurray, 1992) or five (aa 54-73, 327-348, 364-385, 407-426 and 428-447; Frost et al., 1994) transmembrane $\alpha$-helices, as well as a putative Cterminal fragment $\left(\mathrm{TraG}^{*}\right.$, aa $\left.452-938\right)$ in the periplasm (Achtman et al., 1972; Manning et al., 1981; Firth \& Skurray, 1992). TraG was confirmed to localize to the inner membrane, using density flotation gradients to separate inner and outer membranes. The fractions were analysed by immunoblotting using antibodies to TraG, as well as known inner (CpxA, TraD; Weber \& Silverman, 1988; Panicker \& Minkley, 1992) and outer membrane proteins (OmpA; Sonntag et al., 1978) (Fig. 2).

The presence of $\mathrm{TraG}^{\star}$ in the periplasmic space (Firth \& Skurray, 1992) was an intriguing idea that merited further exploration, since it would explain the need for the Cterminal region of TraG for Mps. TraG was detected as a faint band in single-copy $\mathrm{F}+$ cells, but $\mathrm{TraG}^{\star}$ could have been below the limits of detection (data not shown). The existence of $\mathrm{TraG}^{*}$ was further assessed in periplasmic fractions from cells carrying pBAD24 derivatives of either wild-type TraG or a signal peptidase-resistant mutant (TraGA452P) (Fig. 3). These were compared to pelBTraG ${ }^{\star}$, which is a fusion of the putative $\operatorname{TraG}^{\star}$ sequence to the PelB signal sequence to ensure transport to the periplasm. In cells expressing pelBTraG ${ }^{\star}$, the TraG-derived polypeptide was present in the periplasmic fraction, and acted as a size marker for the putative $\operatorname{TraG}^{\star}$ protein $(52.7 \mathrm{kDa})$. When cellular lysates or periplasmic shock fractions were probed with an anti-TraG antibody, fulllength TraG and associated degradation products were found in cell lysates containing TraG or the TraGA452P mutant, whereas no TraG-derived bands were found in the periplasm. We conclude that $\mathrm{TraG}^{\star}$ does not exist under normal circumstances. Immunoblots of mating cells did not reveal a band that could be interpreted as $\operatorname{TraG}^{\star}$ (data not shown), suggesting that it is not generated during Mpf.

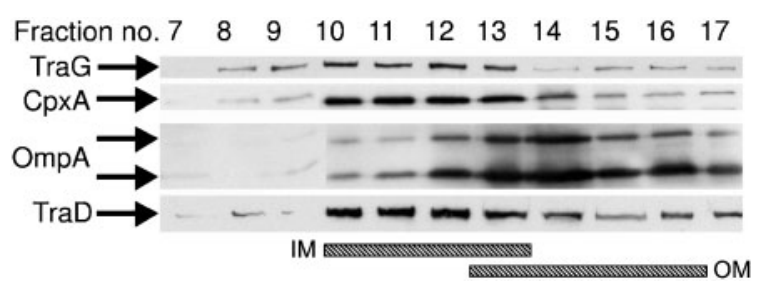

Fig. 2. Localization of TraG in the inner membrane. Inner (IM) and outer (OM) membranes were separated by sucrose density flotation, and proteins were detected by Western blot analysis. TraG was observed to reside predominantly in fractions containing known inner-membrane proteins CpxA and TraD, but not the outer-membrane protein OmpA. The fraction numbers from the gradient are shown along the top, and the positions of the test proteins are shown on the left. The two arrows for OmpA indicate the two bands that were detected with OmpA antiserum.

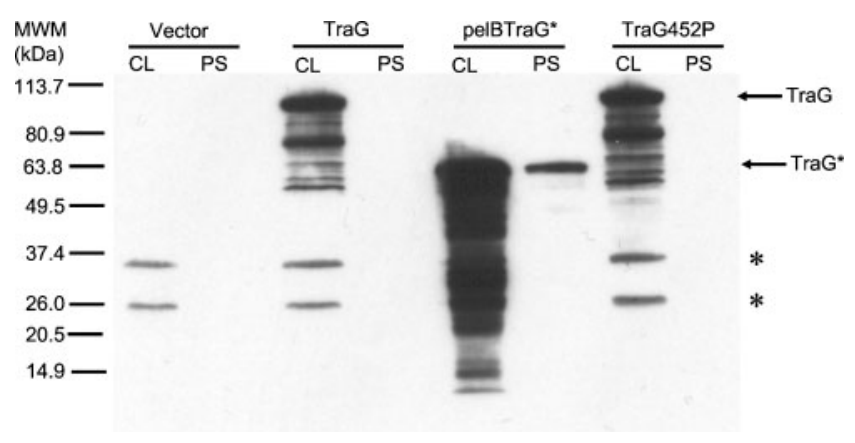

Fig. 3. $\mathrm{TraG}^{\star}$ was not found in the periplasmic space. Western blot analysis of XK1200/pOX38::Tc $\Delta K m$ plus pBAD24 (vector) constructs for TraG, TraG* (pelBTraG*) and TraGA452P in cell lysates $(\mathrm{CL})$ and periplasmic shock fluid (PS) were performed using a polyclonal anti-TraG antibody. The positions of $\operatorname{TraG}(102.5 \mathrm{kDa})$ and $\mathrm{TraG}^{*}$ derived from pelBTraG $(52.7 \mathrm{kDa})$ are shown on the right, and molecular mass markers (MWM) are on the left. Non-specific bands present in all cleared lysates are marked with asterisks.

The predicted topology of TraG (Firth \& Skurray, 1992; Frost et al., 1994) was examined using ISphoA/in insertions that can be converted to in-frame 31 aa epitope fusions, as described by Manoil \& Bailey (1997). Twelve separate ISphoA/in insertions into TraG were obtained in four unique sites in TraG [aa D159 (one insertion), N163 (six insertions), L716 (one insertion) and E739 (four insertions)]. D159 and N163 resided in the first predicted periplasmic loop (aa 74-326), and L716 and E739 were within the C-terminal domain of TraG that extended into the periplasm (Fig. 4). No inserts were isolated for the second predicted periplasmic domain (aa 386-406), possibly because the target was too small (60 bp), or because there are three, not five, transmembrane helices. Only the insert at codon E739 (pBKG739) could be converted to a stable 31 a fusion. Using a complementation assay with pOX38::Tc $\Delta \mathrm{GKm}$, pBKG739 had a mating efficiency that was $15 \%$ of that of the wild-type, suggesting that insertion of the 31 aa in the periplasmic domains greatly affected TraG function.

The nature of the mutations originally described by Willetts \& Achtman (1972) was characterized by sequencing clones of each of the mutant traG genes. The mutations in traG106 and traG101 were +1 frameshifts in runs of Gs or Cs starting at nt 19795 and 21606 (aa T131 and T735), respectively, according to the sequence presented by Frost et al. (1994) (Fig. 4). The mutation in traG79 was a $\mathrm{C}$ to $\mathrm{T}$ transition at nt 21341, resulting in a glutamine (CAG, Q647) changing to an amber codon (Fig. 4).

\section{Mps requires full-length TraG}

We asked whether $\operatorname{TraG}^{\star}$ alone, expressed as pelBtraG ${ }^{\star}$ (ppelBTraG ${ }^{*}$ ), could complement a frame-shift mutant capable of synthesizing pili (FlactraG101), with 


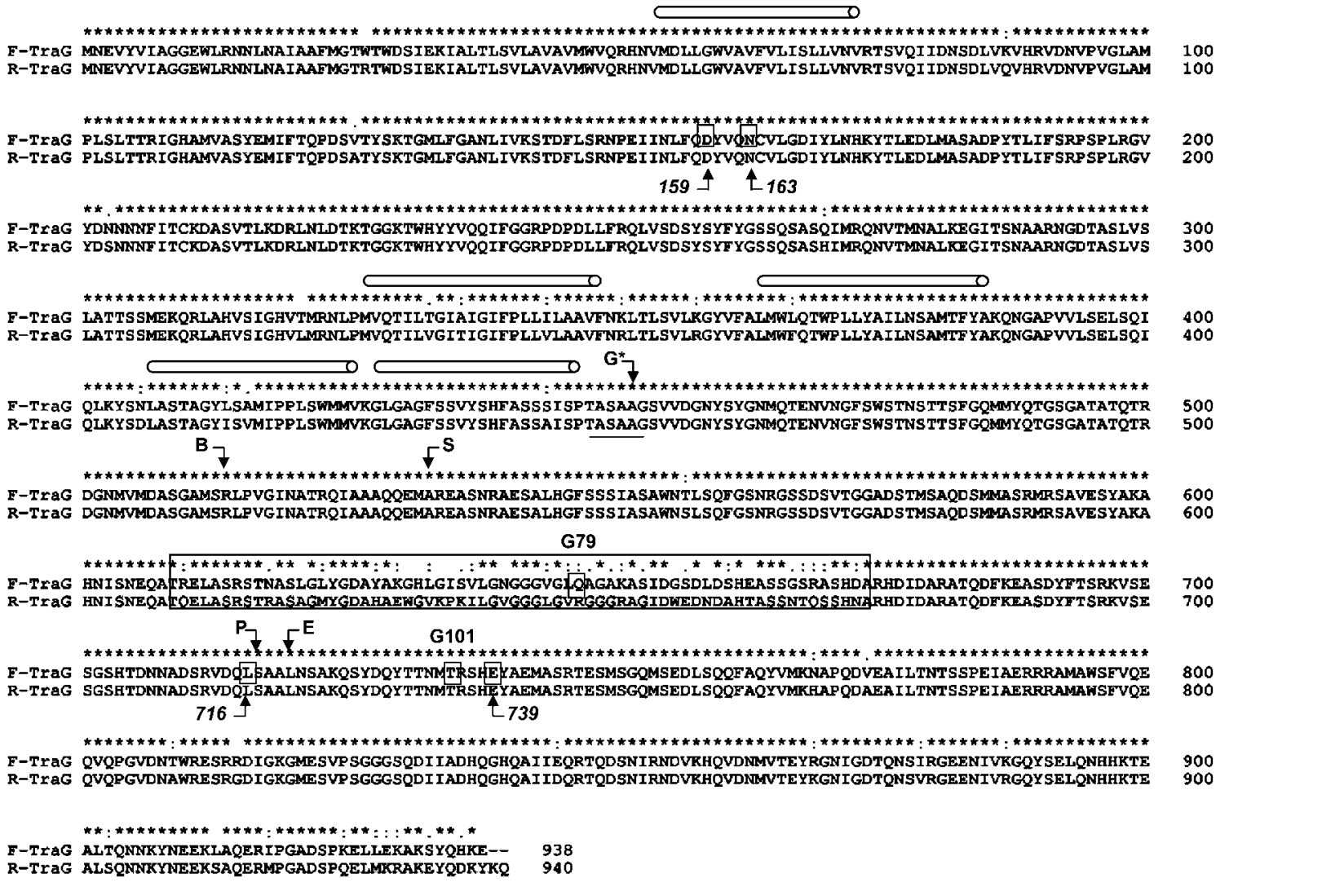

Fig. 4. Sequence alignment of the TraG proteins from the $F$ and $R 100$ plasmids. Alignments of the complete $F$ TraG (NP_061478) and R100 TraG (NP_052976) proteins are shown, with strictly, highly and moderately conserved residues indicated by the symbols '*', ':' and ' $"$, respectively. The region between residues 610 and 673 (boxed) displays the greatest dissimilarity between the two proteins, at $55.7 \%$ identity versus $93 \%$ overall identity between the two proteins. Restriction sites in the corresponding DNA sequence for BstEll (B, nt 1541/aa 514), Smal (S, nt 1600/aa 533), Pstl (P, nt 2154/aa 717) and $E_{c o R I}(E$, nt 2160/aa 720), used to generate the chimeras, are indicated by arrows above the sequence. The five transmembrane helices (aa 54-73, 327-348, 364-385, 407-426 and 428-447) are indicated by cylinders above the sequences. The predicted signal peptidase cleavage site ( $\mathrm{G}^{*}$; Frost et al., 1994) is at residue 451, and the residues forming the -3 to +1 peptidase region (aa 449-452) are underlined. Highlighted amino acids are boxed. T131, Q647 and T735 are the amino acids affected by the traG106, traG79 and traG101 mutations, respectively; 159, 163, 716 and 739 (italic type) are the sites of ISphoA/in insertions at the codons for D159, N163, L716 and E739, respectively.

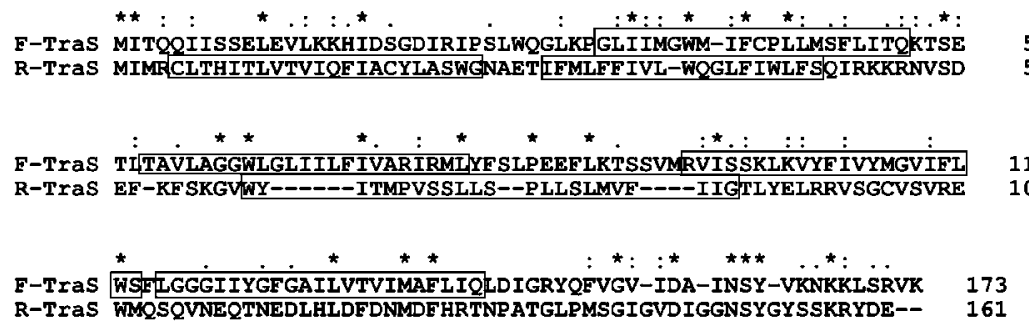

Fig. 5. Sequence alignment of the TraS proteins from the $F$ and R100 plasmids. F TraS (NP_061479) and R100 TraS (NP_052977) showed an overall sequence identity of $17 \%$, with no single region displaying greater identity. Strictly, highly and moderately conserved residues are indicated by the symbols '*', ':' and '.', respectively. Predicted transmembrane helices are boxed. 
Table 1. Mps requires full-length TraG

ND, Not determined.

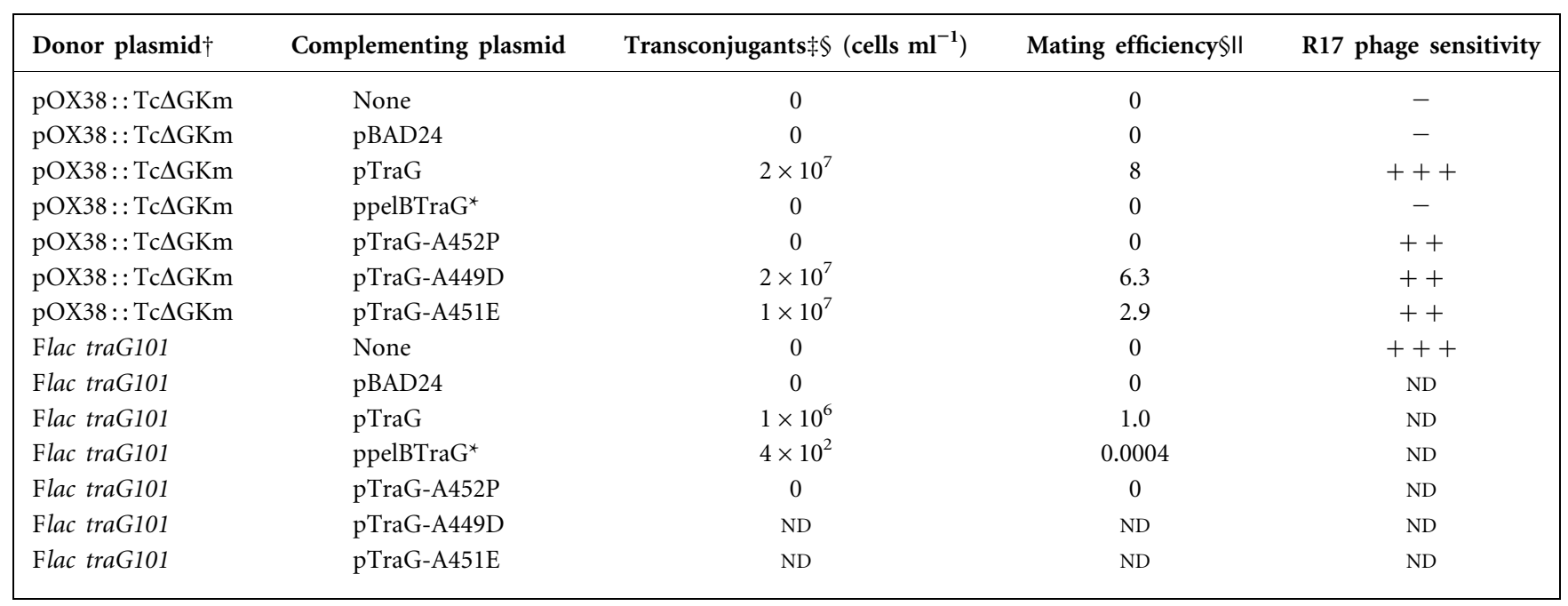

$\dagger$ Donor cells were E. coli XK1200/pOX38::Tc AGKm or XK1200/Flac traG101 with the constructs listed in the next column, and cell

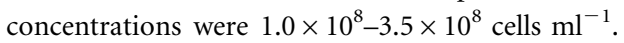

$\ddagger$ Recipient cells were E. coli MC4100. 0 indicates no transconjugants in a $10^{-2}$ dilution.

$\$$ An average of two to four mating experiments were performed for each construct.

IIMating efficiency was defined as transconjugants per 100 donor cells. 0 mating efficiency indicates no transconjugants at a $10^{-2}$ dilution.

pOX38:: Tc $\Delta G K m$ acting as a control. Using mating experiments, only clones expressing full-length TraG could complement both pOX38::Tc $\Delta \mathrm{GKm}$ and FlactraG101 donors (Table 1 ). ppelBTraG ${ }^{\star}$ partially complemented FlactraG101 at very low levels in some assays, which was thought to be due to reversion of the frameshift mutation in FlactraG101.

Based on studies of the amino acid requirements at the signal peptidase I cleavage site (von Heijne, 1983), mutations that are predicted to severely alter peptidase activity were introduced into TraG by site-directed mutagenesis at positions $-3,-1$ and +1 of the predicted cleavage site [residues 449-452 (ASA-A); G*, Figs 1 and 4]. Thus +1 alanine was converted to proline (A452P), - 1 alanine to glutamic acid (A551E), and the -3 alanine to aspartic acid (A449D). These mutations were introduced into pTraG and used in complementation assays with pOX38:: Tc $\Delta$ GKm and FlactraG101, which synthesizes F pili (Table 1). The lack of complementation by pTraGA452P suggested either that the proline altered the conformation of TraG or that A452 was indeed important for TraG function. However, two other point mutations, TraGA449D and TraGA451E, complemented pOX38:: Tc $\Delta \mathrm{GKm}$ and gave $40-80 \%$ of wild-type results for pOX38:: Tc $\Delta \mathrm{GKm} / \mathrm{pTraG}$ (Table 1). We conclude that there is no signal peptidase I cleavage site in the middle of TraG, and that the proline at position 452 likely introduced a kink into the periplasmic domain that affected TraG function in Mps. Thus, full-length TraG is required for Mps with both the $\mathrm{N}$ - and $\mathrm{C}$-terminal regions participating in establishing stable mating junctions.

\section{Eex involves plasmid-specific recognition between TraG and TraS}

Eex is a plasmid-specific process, defined by TraS in the recipient cell, which blocks DNA transport between cells carrying the same conjugative plasmids (Ou, 1975; Kingsman \& Willetts, 1978) by recognizing its cognate TraG in the donor cell (Anthony et al., 1999; Marrero \& Waldor, 2005). While the F and R100 TraS clones were being constructed, we realized that the sequences originally presented for R100 TraS (Ogata et al., 1982) and F TraS (Jalajakumari et al., 1987) were incorrect. The correct accession numbers are NP_061479 (F TraS; gi398520) and NP_052977 (R100 TraS; gi5036330), based on more recent sequence data (Fig. 5). TraS was fused to a His6 tag at both the $\mathrm{N}$ and $\mathrm{C}$ termini, and tested for Eex using mating efficiency assays. Both fusions gave Eex comparable to wildtype TraS (Table 2). Using anti-His6 antibodies, the presence of TraS, expressed from a pBAD24 clone that was induced with $0.05 \%$ arabinose, was confirmed to be in the inner membrane by flotation density gradient analysis (data not shown).

The specificity of putative TraG-TraS interactions was examined using a series of F TraG/R100 TraG chimeras (Fig. 1) that were assessed for their ability to restore Eex in traG-deficient donor cells (pOX38:: Tc $\Delta$ GKm; Table 3). When native TraG ( $\operatorname{TraG}_{\mathrm{FFF}}$ or $\left.\operatorname{TraG}_{\mathrm{RRR}}\right)$ was assessed, only 
Table 2. Eex through TraG and TraS occurs in trans

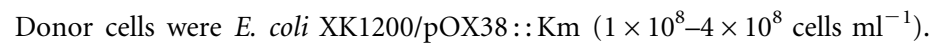

\begin{tabular}{|c|c|c|c|}
\hline Recipient $\dagger$ & Transconjugants $\ddagger\left(\right.$ cells $\mathbf{m l}^{-1}$ ) & Mating efficiency $\S$ & Eex indexll \\
\hline pBAD24-TraS ${ }_{F}$ & $4.5 \times 10^{3}$ & 0.0015 & 3.0 \\
\hline pBAD24-6HTraS ${ }_{F}$ & $2.0 \times 10^{3}$ & 0.0011 & 3.35 \\
\hline pBAD33 & $1.5 \times 10^{7}$ & 10 & 0 \\
\hline pBAD24 + pBAD33 & $5.0 \times 10^{6}$ & 4.0 & 0 \\
\hline $\mathrm{pBAD} 33-\operatorname{TraG}_{\mathrm{F}}+\mathrm{pBAD} 24-\operatorname{TraS}_{\mathrm{F}}$ & $2.0 \times 10^{3}$ & 0.0010 & 3.4 \\
\hline pBAD33-TraG ${ }^{*}+$ pBAD24 $-\operatorname{TraS}_{\mathrm{F}}$ & $3.5 \times 10^{3}$ & 0.0012 & 3.2 \\
\hline
\end{tabular}

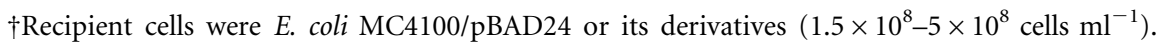

¥Mating experiments were done in duplicate.

$\$$ Mating efficiency was defined as transconjugants per 100 donor cells.

IIEex index was defined as the log of MC4100/pBAD24 (pBAD33) transconjugants minus the log of MC4100/F or R100 TraS transconjugants. Eex $<0$ was counted as no entry exclusion.

Table 3. Eex by F and R100 TraG chimeras (defined in Fig. 4)

\begin{tabular}{|c|c|c|c|c|}
\hline Donor pOX38: : TcsGKm & Recipient $\dagger$ & Transconjugants $\ddagger\left(\right.$ cells $\mathrm{ml}^{-1}$ ) & Mating efficiency $\ddagger \S$ & Eex index $\neq \|$ \\
\hline pBAD24 & pBAD24 & 0 & 0 & - \\
\hline \multirow[t]{3}{*}{$\mathrm{pTraG}_{\mathrm{FFF}}$} & MC4100 & $1.7 \times 10^{8}$ & 68 & 0 \\
\hline & $\mathrm{pTraS}_{\mathrm{F}}$ & $2.3 \times 10^{4}$ & 0.006 & 3.9 \\
\hline & $\mathrm{pTraS}_{\mathrm{R} 100}$ & $2.2 \times 10^{7}$ & 11 & 0.9 \\
\hline \multirow[t]{3}{*}{ pTraG } & MC4100 & $1.7 \times 10^{8}$ & 57 & 0 \\
\hline & $\mathrm{pTraS}_{\mathrm{F}}$ & $2 \times 10^{4}$ & 0.005 & 3.9 \\
\hline & $\mathrm{pTraS}_{\mathrm{R} 100}$ & $2.3 \times 10^{7}$ & 4.6 & 0.9 \\
\hline \multirow[t]{3}{*}{$\mathrm{p} T r a G_{\mathrm{RFR}}$} & MC4100 & $2 \times 10^{8}$ & 50 & 0 \\
\hline & $\mathrm{pTraS}_{\mathrm{F}}$ & $7 \times 10^{4}$ & 0.018 & 3.5 \\
\hline & $\mathrm{pTraS}_{\mathrm{R} 100}$ & $3.5 \times 10^{7}$ & 8.8 & 0.8 \\
\hline \multirow{3}{*}{ pTraG $\operatorname{RFF}$} & MC4100 & $2 \times 10^{8}$ & 80 & 0 \\
\hline & $\mathrm{pTraS}_{\mathrm{F}}$ & $1 \times 10^{4}$ & 0.005 & 4.0 \\
\hline & $\mathrm{pTraS}_{\mathrm{R} 100}$ & $2.8 \times 10^{7}$ & 14 & 0.9 \\
\hline \multirow[t]{3}{*}{$\mathrm{pTraG}_{\mathrm{RRR}}$} & MC4100 & $1.2 \times 10^{8}$ & 40 & 0 \\
\hline & $\mathrm{pTraS}_{\mathrm{F}}$ & $5.6 \times 10^{8}$ & 187 & 0.3 \\
\hline & $\mathrm{pTraS}_{\mathrm{R} 100}$ & $7.7 \times 10^{4}$ & 0.019 & 3.2 \\
\hline \multirow[t]{3}{*}{ pTraG ${ }_{R R F}$} & MC4100 & $1.2 \times 10^{8}$ & 60 & 0 \\
\hline & $\mathrm{pTraS}_{\mathrm{F}}$ & $5.5 \times 10^{6}$ & 2.2 & 1.4 \\
\hline & $\mathrm{pTraS}_{\mathrm{R} 100}$ & $5.5 \times 10^{4}$ & 0.018 & 3.0 \\
\hline \multirow[t]{3}{*}{$\mathrm{pTraG}_{\mathrm{FRF}}$} & MC4100 & $2.1 \times 10^{7}$ & 15 & 0 \\
\hline & $\mathrm{pTraS}_{\mathrm{F}}$ & $1.8 \times 10^{5}$ & 0.18 & 2.1 \\
\hline & $\mathrm{pTraS}_{\mathrm{R} 100}$ & $9.3 \times 10^{3}$ & 0.005 & 3.4 \\
\hline \multirow[t]{3}{*}{ pTraG ${ }_{\text {FRR }}$} & MC4100 & $5.5 \times 10^{7}$ & 27.5 & 0 \\
\hline & $\mathrm{pTraS}_{\mathrm{F}}$ & $9.5 \times 10^{6}$ & 4.8 & 0.8 \\
\hline & $\mathrm{pTraS}_{\mathrm{R} 100}$ & $5.5 \times 10^{3}$ & 0.003 & 4.0 \\
\hline
\end{tabular}

${ }^{\star}$ Donor cells were E. coli XK1200/pOX38:: Tc $\Delta \mathrm{GKm}\left(1.5 \times 10^{8}-4 \times 10^{8}\right.$ cells ml $\left.^{-1}\right)$.

$\dagger$ Recipients were E. coli MC4100 with pBAD24 or its derivatives.

$\ddagger$ An average of three mating experiments were performed.

\Mating efficiency was defined as transconjugants per 100 donor cells.

IIEex index was defined as the log of MC4100 transconjugants minus the log of MC4100 with F or R100 TraS transconjugants. 
the corresponding $\operatorname{TraS}$ (F or R100, respectively) in the recipient cell gave Eex. This was narrowed down to the middle region of TraG (aa 533-717 in F), since this region was required for recognition of the cognate TraS in the recipient cell (Table 3). All other TraG chimeras had low to undetectable Eex. With the exception of a single amino acid difference at position 558 ( $\mathrm{S}$ to $\mathrm{T}$ ), the only differences in the sequences of aa 533-717 in F and R100 TraG were within aa 610-673 (Fig. 4), which further delimits the region of TraG involved in Eex.

The ability to interfere with TraS function by co-producing TraG or $\mathrm{TraG}^{*}$ in the recipient cell was monitored using an Eex assay (Table 2). Neither TraG nor TraG* interfered with Eex, suggesting that TraG and TraS interacts in trans between donor and recipient cells. Thus, TraG must be delivered to the recipient cell inner membrane by a process that defines the phenomenon of Mps.

\section{DISCUSSION}

The traG gene product has been shown to be involved in both pilus synthesis and Mps (Manning et al., 1981). Sequence homology has been noted between the N-terminal domain of TraG and VirB6, a polytopic inner-membrane protein of the Ti plasmid of Agrobacterium tumefaciens also involved in T pilus synthesis and T-DNA transport (Lawley et al., 2003). However, unlike Ti VirB6, which is predicted to contain between four and nine transmembrane helices (Christie, 2001; Judd et al., 2005), TraG is predicted by hydropathy plot analysis (Firth \& Skurray, 1992; Frost et al., 1994) to span the inner membrane three to five times, with large periplasmic regions at approximately aa $75-325$ and 445-938 (C terminus). Our limited number of ISphoA/in insertions confirmed these results, and suggested that there were at least three transmembrane domains. Interestingly, the only ISphoA/in insertion that could be converted to a stable 31 aa epitope fusion (at E739) is very close to the traG101 frameshift mutation at T735 that affects Mps but not pilus synthesis. No evidence was observed for $\operatorname{TraG}^{*}$, a periplasmic fragment suggested to be involved in Mps (Firth \& Skurray, 1992). Degradation products in the lysate of cells overproducing $\mathrm{TraG}$ were approximately correct in size (Fig. 3), but none of these products was found in the periplasm. The observation that $\mathrm{TraG}$, but not $\mathrm{TraG}^{*}$, can fully complement FlactraG101 suggests that whole TraG is required for biological activity, which also argues against the presence of $\mathrm{TraG}^{*}$.

Examination of the ability of F or R100 transfer proteins to complement $\mathrm{F}$ tra mutations and affect phage sensitivity or Eex suggests that TraG in the donor cell is specific for its cognate TraS in the recipient cell (Anthony et al., 1999). A comparison of the sequences of TraG from the F and R100 plasmids indicates that they share an overall sequence identity of $93 \%$. However, the region between residues 610 and 673 of TraG shows the most dissimilarity, with an overall sequence identity of $55.7 \%$ (Fig. 4). This region is within the portion of TraG in the chimeric plasmids (aa 533-717) that exhibits specificity for TraS, and is probably responsible for this phenomenon.

Unlike TraG, TraS from F and R100 plasmids were highly distinct, exhibiting only $17 \%$ sequence identity (Fig. 5). The orientations of F and R100 TraS in the membrane were difficult to predict and could be quite different for the two proteins. Using the TMHMM algorithm, three or four transmembrane helices were predicted for R100 and F TraS, respectively, but in significantly different locations. Thus, there is no limited region of dissimilarity in $\operatorname{TraS}$ to aid in predicting the features that are recognized by TraG. Marrero \& Waldor (2005), who have studied Eex specificity in the more closely related SXT and R391 systems, have been able to narrow the specificity region of $\mathrm{TraG}$ to three amino acids, aa 606-608, which approximates the location of the dissimilar region in F and R100 TraG (aa 610-673). They have also been able to identify the C-terminal half of TraS as being responsible for Eex specificity. Our attempts to construct stable TraS chimeras were unsuccessful, possibly due to incorrect insertion of the chimeras in the membrane.

TraG is involved in pilus synthesis as well as Mps; therefore, it would be expected to interact with other proteins in the donor cell, although none have so far been identified. There has been speculation that TraG might form a transenvelope bridge and contact $\mathrm{TraN}$ in the outer membrane (Firth \& Skurray, 1992); however, this interaction has not been detected using cross-linking (Klimke et al., 2005). We are currently exploring the possibility that TraG interacts with TraU, which is a putative Mps protein, and is known to be part of an interaction complex that is involved in pilus synthesis, but is not itself required for this process (Moore et al., 1990; Harris \& Silverman, 2004).

This report further defines a third function of TraG, that of Eex through interaction with TraS in the recipient cell. This function is plasmid-specific and appears to involve aa 610-673 of TraG. This TraG-TraS interaction occurs in trans between a donor (TraG) and recipient cell ( $\mathrm{TraS})$; supplying TraG or $\mathrm{TraG}^{*}$ in the recipient cell did not affect mating or Eex. As both TraG and TraS are inner-membrane proteins, the mechanism by which they recognize each other is puzzling. Since Mps involves close contact between mating cells that is difficult to disrupt (Achtman, 1975), a process can be envisioned whereby $\mathrm{F}$ TraN binds OmpA in the recipient outer membrane and triggers pore formation. TraG would then be thrust into the periplasmic space to establish contact with the inner membrane of the recipient cell. If $\operatorname{TraS}$ interferes with this signalling mechanism, conjugative DNA synthesis and transfer are blocked. Attempts to isolate a TraG-TraS complex from mating cells by cross-linking or immunoprecipitation, or to demonstrate interaction using a bacterial two-hybrid system, have been unsuccessful. This appears to be due to the small percentage of the total amount of TraG or TraS involved in a single mating bridge, and possibly a 
requirement for higher-order multimeric structures for correct interaction between TraS and TraG.

\section{ACKNOWLEDGEMENTS}

We wish to thank Drs Bart Hazes and Erin van Schaik (University of Alberta) for useful discussions. This research was supported by operating grants to L.S.F. from the Canadian Institutes for Health Research (62776) and Natural Sciences and Engineering Research Council (139684).

\section{REFERENCES}

Achtman, M. (1975). Mating aggregates in Escherichia coli conjugation. J Bacteriol 123, 505-515.

Achtman, M., Willetts, N. \& Clark, A. J. (1971). Beginning a genetic analysis of conjugational transfer determined by the $\mathrm{F}$ factor in Escherichia coli by isolation and characterization of transfer-deficient mutants. J Bacteriol 106, 529-538.

Achtman, M., Willetts, N. \& Clark, A. J. (1972). Conjugational complementation analysis of transfer-deficient mutants of Flac in Escherichia coli. J Bacteriol 106, 529-538.

Achtman, M., Kennedy, N. \& Skurray, R. (1977). Cell-cell interactions in conjugating Escherichia coli: role of traT protein in surface exclusion. Proc Natl Acad Sci U S A 74, 5104-5108.

Anthony, K. G., Sherburne, C., Sherburne, R. \& Frost, L. S. (1994). The role of the pilus in recipient cell recognition during bacterial conjugation mediated by F-like plasmids. Mol Microbiol 13, 939-953.

Anthony, K. G., Klimke, W. A., Manchak, J. \& Frost, L. S. (1999). Comparison of proteins involved in pilus synthesis and mating pair stabilization from the related plasmids F and R100-1: insights into the mechanism of conjugation. J Bacteriol 181, 5149-5159.

Bradley, D. E., Taylor, D. E. \& Cohen, D. R. (1980). Specification of surface mating systems among conjugative drug resistance plasmids in Escherichia coli K-12. J Bacteriol 143, 1466-1470.

Christie, P. J. (2001). Type IV secretion: the Agrobacterium BirB/D4 and related conjugation systems. Biochim Biophys Acta 1694, 219-234.

Durrenberger, M. B., Villiger, W. \& Bachi, T. (1991). Conjugational junctions: morphology of specific contacts in conjugating Escherichia coli bacteria. J Struct Biol 107, 146-156.

Firth, H. \& Skurray, R. (1992). Characterization of the F plasmid bifunctional conjugation gene, traG. Mol Gen Genet 1, 145-153.

Frost, L. S., Ippen-Ihler, K. \& Skurray, R. A. (1994). Analysis of the sequence and gene products of the transfer region of the $\mathrm{F}$ sex factor. Microbiol Rev 58, 162-210.

Grahn, A. M., Haase, J., Bamford, D. H. \& Lanka, E. (2000). Components of the RP4 conjugative transfer apparatus form an envelope structure bridging inner and outer membranes of donor cells: implications for related macromolecule transport systems. J Bacteriol 182, 1564-1574.

Guzman, L. M., Belin, D., Carson, M. J. \& Beckwith, J. (1995). Tight regulation, modulation, and high-level expression by vectors containing the arabinose PBAD promoter. J Bacteriol 177, 4121-4130.

Harris, R. L. \& Silverman, P. M. (2004). Tra proteins characteristic of F-like type IV secretion systems constitute an interaction group by yeast two-hybrid analysis. J Bacteriol 186, 5480-5485.

Harrison, J. L., Taylor, I. M., Platt, K. \& O'Connor, C. D. (1992). Surface exclusion specificity of the TraT lipoprotein is determined by single alterations in a five amino acid region of the protein. $\mathrm{Mol}$ Microbiol 6, 2825-2832.
Jalajakumari, M. B., Guidolin, A., Buhk, H. J., Manning, P. A., Ham, L. M., Hodgson, A. L. M., Cheah, K.-C. \& Skurray, R. A. (1987). Surface exclusion genes traS and traT of the $\mathrm{F}$ sex factor of Escherichia coli K-12. Determination of the nucleotide sequence and promoter and terminator activities. J Mol Biol 198, 1-11.

Judd, P. K., Mahli, D. \& Das, A. (2005). Molecular characterization of the Agrobacterium tumefaciens DNA transfer protein VirB6. Microbiology 151, 3483-3492.

Kingsman, A. \& Willetts, N. (1978). The requirements for conjugal DNA synthesis in the donor strain during Flac transfer. J Mol Biol 122, 287-300.

Klimke, W. A. \& Frost, L. S. (1998). Genetic analysis of the role of the transfer gene, traN, of the $\mathrm{F}$ and R100-1 plasmids in mating pair stabilization during conjugation. J Bacteriol 180, 4036-4043.

Klimke, W. A., Rypien, C. D., Klinger, B. A., Kennedy, R. A., Rodriguez-Maillard, J. M. \& Frost, L. S. (2005). The mating pair stabilization protein, TraN, of the F plasmid, is an outer membrane protein with two regions that are important for its function in conjugation. Microbiology 151, 3527-3540.

Krogh, A., Larsson, B., von Heijne, G. \& Sonnhammer, E. L. L. (2001). Predicting transmembrane protein topology with a hidden Markov model: application to complete genomes. J Mol Biol 305, 567-580.

Lawley, T., Klimke, W. A., Gubbins, M. J. \& Frost, L. S. (2003). F factor is a true type IV secretion system. FEMS Microbiol Lett 224, 1-15.

Lawley, T., Wilkins, B. M. \& Frost, L. S. (2004). Bacterial conjugation in Gram-negative bacteria. In Plasmid Biology, pp. 203-226. Edited by B. E. Funnell \& G. J. Phillips. Washington, DC: American Society for Microbiology.

Lederberg, J. (1956). Conjugal pairing in Escherichia coli. J Bacteriol 71, 497-498.

Manning, P. A., Morelli, G. \& Achtman, M. (1981). TraG protein of the F sex factor of Escherichia coli K-12 and its role in conjugation. Proc Natl Acad Sci U S A 78, 7487-7491.

Manoil, C. \& Bailey, J. (1997). A simple screen for permissive sites in proteins: analysis of Escherichia coli lac permease. J Mol Biol 267, 250-263.

Marrero, J. \& Waldor, M. K. (2005). Interactions between inner membrane proteins in donor and recipient cells limit conjugal DNA transfer. Dev Cell 8, 963-970.

Moore, D., Maneewannakul, K., Maneewannakul, S., Wu, J. H., Ippen-Ihler, K. \& Bradley, D. B. (1990). Characterization of the F plasmid conjugative transfer gene traU. J Bacteriol 172, 4263-4270.

Ochman, H., Lawrence, J. G. \& Groisman, E. A. (2000). Lateral gene transfer and the nature of bacterial innovation. Nature 405, 299-304.

Ogata, R. T., Winters, C. \& Levine, R. P. (1982). Nucleotide sequence analysis of the complement resistance gene from plasmid R100. $J$ Bacteriol 151, 819-827.

Ou, J. T. (1975). Mating signal and DNA penetration deficiency in conjugation between male Escherichia coli and minicells. Proc Natl Acad Sci U S A 72, 3721-3725.

Panicker, M. M. \& Minkley, E. G., Jr (1992). Purification and properties of the F sex factor TraD protein, an inner membrane conjugal protein. J Biol Chem 267, 12761-12766.

Sonntag, I., Schwarz, H., Hirota, Y. \& Henning, U. (1978). Cell envelope and shape of Escherichia coli: multiple mutants missing the outer membrane lipoprotein and other major outer membrane proteins. J Bacteriol 136, 280-285.

Thompson, J. D., Higgins, D. G. \& Gibson, T. J. (1994). CLUSTAL W: improving the sensitivity of progressive multiple sequence alignment 
through sequence weighting, position-specific gap penalties and weight matrix choice. Nucleic Acids Res 22, 4673-4680.

von Heijne, G. (1983). Patterns of amino acids near signal-sequence cleavage sites. Eur J Biochem 133, 17-21.

Weber, R. F. \& Silverman, P. M. (1988). The Cpx proteins of Escherichia coli K12: structure of the CpxA polypeptide as an inner membrane component. J Mol Biol 203, 467-476.
Wilkins, B. M. \& Frost, L. S. (2001). Mechanisms of gene exchange between bacteria. In Molecular Medical Microbiology, pp. 355-400. Edited by M. Sussman. London: Academic Press.

Willetts, N. \& Achtman, M. (1972). Genetic analysis of transfer by the Escherichia coli sex factor F, using P1 transductional complementation. J Bacteriol 110, 843-851.

Edited by: L. Jannière 